\title{
Increasing Participation Rates in Germany's Skin Cancer Screening Program (HELIOS): Protocol for a Mixed Methods Study
}

Theresa Steeb ${ }^{1,2}$, MPH; Markus V Heppt ${ }^{1,2}$, MSc, MHBA, MD; Michael Erdmann ${ }^{1,2}$, MD; Anja Wessely ${ }^{1,2}$, MSc; Stefanie J Klug ${ }^{3}$, MPH, PhD; Carola Berking ${ }^{1,2}$, MD

${ }^{1}$ Department of Dermatology, University Hospital Erlangen, Friedrich-Alexander-University Erlangen-Nuremberg, Erlangen, Germany

${ }^{2}$ Comprehensive Cancer Center Erlangen - European Metropolitan Region of Nuremberg, Erlangen, Germany

${ }^{3}$ Chair of Epidemiology, Department of Sport and Health Sciences, Technical University of Munich, Munich, Germany

Corresponding Author:

Theresa Steeb, MPH

Department of Dermatology

University Hospital Erlangen

Friedrich-Alexander-University Erlangen-Nuremberg

Ulmenweg 18

Erlangen, 91054

Germany

Phone: 491318545852

Email: theresa.steeb@uk-erlangen.de

\section{Abstract}

Background: In 2008, a nationwide skin cancer screening (SCS) program was implemented in Germany. However, participation rates remain low.

Objective: The overall objective of the HELIOS study is to identify subgroup-specific invitation and communication strategies to increase informed SCS participation in Germany.

Methods: Focus group discussions will be performed in Erlangen, Germany, to explore potential invitation and communication strategies as well as possible barriers and motivating factors to participate in SCS. Male and female patients of different age groups who have already been diagnosed with skin cancer, as well as participants without a prior diagnosis of skin cancer, will be invited. Based on these results, an online questionnaire will be developed to identify subgroup-specific invitation strategies. A random sample of 2500 persons from the general population aged $>35$ years from the Munich area will be contacted to complete the questionnaire. Besides descriptive analysis, multinomial logistic regression will be performed. Additionally, a cluster analysis will be conducted to discover patterns or similarities among the participants.

Results: Recruitment for the focus group studies started in February 2021 and is ongoing. As of August 2021, we have enrolled 39 participants. We expect to end enrollment in the qualitative study in September 2021 and to finish the analysis in December 2021. The second part of the study will then start in January 2022.

Conclusions: The results of this project will enable us to derive improved and more efficient invitation and communication strategies for SCS. These may be implemented in the future to facilitate increased SCS uptake and early skin cancer detection.

International Registered Report Identifier (IRRID): DERR1-10.2196/31860

(JMIR Res Protoc 2021;10(12):e31860) doi: $\underline{10.2196 / 31860}$

\section{KEYWORDS}

skin cancer; melanoma; squamous cell carcinoma; basal cell carcinoma; screening; early detection; focus group; mixed methods; cross-sectional study; prevention

\section{Introduction}

Skin cancer is one of the most frequently diagnosed cancer entities in Germany. The incidence of melanoma and nonmelanoma skin cancer has steadily increased in recent years [1]. Besides reducing exposure to ultraviolet radiation by means of sun protection measures, early detection of suspicious skin lesions represents a key secondary prevention strategy [2,3]. Aiming to reduce skin cancer-associated mortality and 
morbidity, a national skin cancer screening (SCS) program was introduced in Germany in July 2008. It involves a voluntary, standardized full-body examination by dermatologists or general practitioners who have been specifically trained for this purpose. As a part of this examination, risk factors for skin cancer as well as prevention measures are addressed. The costs are reimbursed by all German statutory health insurance companies biannually for members who are $>35$ years, while some health insurance companies also cover SCS costs for younger members [4]. The decision to implement SCS at the population level was based on the results of the pilot SCREEN (Skin Cancer Research to Provide Evidence for Effectiveness in Northern Germany) project [5]. Following this study, there was both a significant decrease in melanoma mortality [6] and a shift in the T-stage distribution in favor of thin melanomas [7]. These differences in comparison to neighboring regions without SCS suggested that they were attributable to SCS, but this has been subject to debate $[6,8]$.

Since its introduction, more than 13 million patients have participated in the SCS program, and estimated participation rates have ranged between $24 \%$ and $39 \%$ [4,9-11]. However, this highlights that about $60 \%$ to $75 \%$ of eligible residents in Germany have never taken advantage of the SCS program. Nevertheless, most people appreciate the option to participate in the SCS program and, additionally, informed persons use SCS more frequently than uninformed persons [9]. Moreover, women undergo SCS more frequently than men [12]. However, unlike the organized invitation programs for mammography, cervical cancer, and colorectal cancer screening, there are currently no campaigns or target group-specific invitation strategies aimed at increasing people's decision to participate in SCS in Germany.

In order to develop target group-specific invitation strategies to ultimately increase the SCS participation rate in Germany, we initiated the HELIOS study (German acronym for Hautkrebsspezifische Einladungsverfahren zur informierten Screeningteilnahme, or in English, Skin Cancer-Specific Invitation Strategies to Participate in the Skin Cancer Screening Program). Here, we describe the study design and summarize the study protocol. The results of our project will contribute to increase participation rates in SCS and thus lead to earlier detection of skin cancer.

\section{Methods}

\section{HELIOS Project}

The HELIOS project comprises two discrete, yet complementary, subprojects. The first part consists of a qualitative approach comprising several focus group sessions with different subgroups in Erlangen, Germany, to exploratively collect possible communication strategies for SCS. The second part is based on the results of the focus group sessions and involves a cross-sectional study among a random sample of residents in Munich, Germany, aimed at identifying suitable, targeted communication strategies for different subgroups (Figure 1). 
Figure 1. (A) Map of Germany showing the location of the 2 subprojects within the federal state of Bavaria. (B) Overview of the study flowchart of the subprojects within the HELIOS project.

A

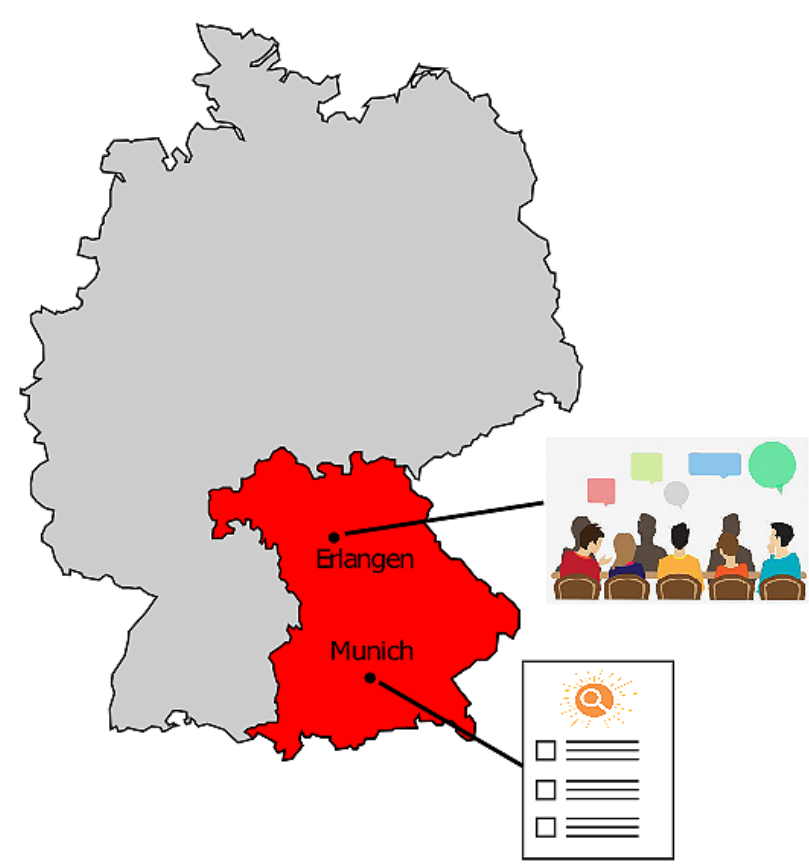

B

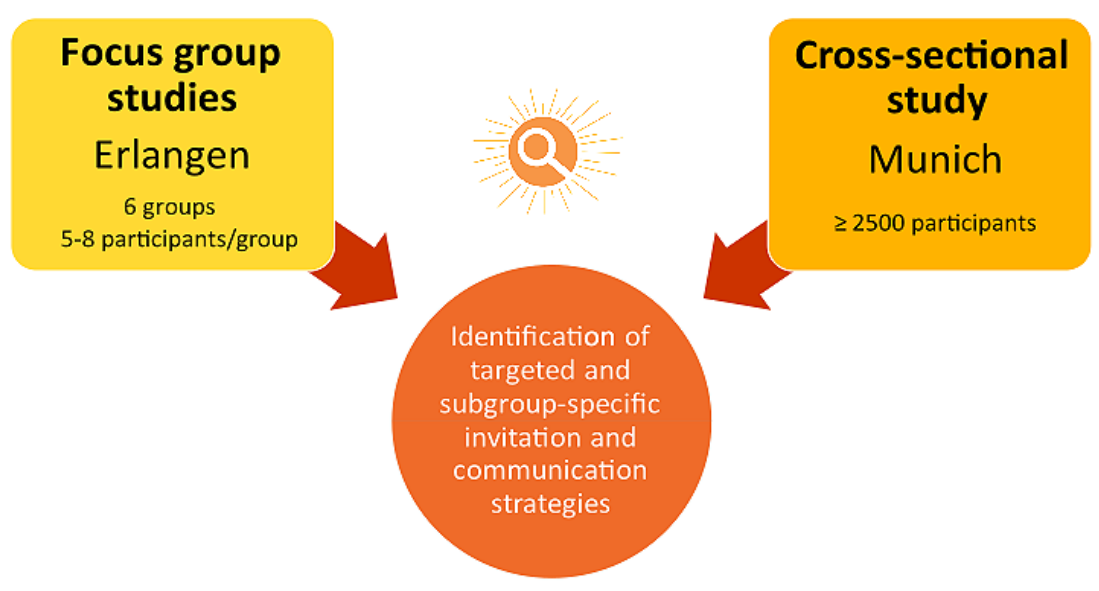

\section{Part 1: Focus Group Study}

\section{Objective and Study Design}

In order to exploratively collect possible invitation procedures and communication approaches for different subgroups, a qualitative and explorative design will be used through focus group discussions. As a part of these discussions, the already existing information brochure Detecting Skin Cancer, of the German Cancer Aid, will be additionally evaluated in order to obtain target group-specific suggestions for improvement [13].

Qualitative approaches facilitate an in-depth picture of patients' preferences and needs $[14,15]$. In addition, the interactive component of the focus groups enables participants to ponder, reflect, and listen to the experiences and opinions of others [16]. The interview will be structured according to published guidelines for focus groups [16]. A manual with questions for the focus groups will be developed by the investigators of this study and will be based on an assessment of the literature and dermato-oncologic experience.

The focus group interviews will assess the following aspects:

1. Willingness to participate in the SCS program with reasons for or against participation;

2. Interest in invitation procedures and preferred communication strategy;

3. Information required for an informed decision for or against participation in the SCS program;

4. Evaluation of the German Cancer Aid's information brochure Detecting Skin Cancer [13] to obtain patient-specific suggestions for improvement.

Follow-up and probing questions will be used for clarification and elaboration. This subproject is particularly important as it takes into account the perspective and view of both participants 
who have not been diagnosed with skin cancer and patients with skin cancer. The semistructured interview guide is available in Multimedia Appendix 1.

\section{Sampling, Recruitment, and Data Collection}

Participants will be recruited via German patient support groups (eg, Hautkrebs-Netzwerk Deutschland, Melanom Info Deutschland), local Facebook groups, as well as through in-hospital flyers and direct contact by attending physicians in the Oncological Outpatient Department of the university hospital (Friedrich-Alexander-Universität Erlangen-Nürnberg). Patients who have already been diagnosed with skin cancer, as well as healthy or previously unaffected participants, will be eligible to participate in the discussions. A total of 6 focus groups of 5 to 8 participants, each with a duration of 45 to 90 minutes, are planned (a total of 30 patient or participant representatives) in Erlangen. The respective groups will differ in terms of gender composition (male/female) and age (35-50 years, 51-65 years, and $>65$ years). The participants will receive a financial incentive for successful participation. The interviews will be audiorecorded and moderated by an experienced interviewer and assistant. Demographic data such as age or gender will be obtained in advance from the participants using an anonymized questionnaire.

\section{Data Analysis}

All sessions will be transcribed verbatim and analyzed by 2 investigators independently, presumably via a qualitative content analysis according to Mayring [16] with the aid of the software MAXQDA (VERBI Software). The transcribed data will not be linked to any patient-identifying information to assure anonymity. Sociodemographic data will be presented descriptively as frequencies (\%); age will be presented as mean or median and range. Prior to the focus groups, we will collect informed consent from each participant. We will closely adhere to the Consolidated Criteria for Reporting Qualitative Research (COREQ) checklist [17].

\section{Part 2: Cross-sectional Study}

\section{Objective and Study Design}

The aim of the second subproject is the identification of target group-specific invitation procedures for the SCS program by means of an anonymized, questionnaire-based cross-sectional study in which the previously identified relevant invitation procedures from the focus group discussions (eg, postal invitation, invitation via email) will be further investigated. The invitation procedures will be correlated with the respective sociodemographic profile of the participants to create a prediction model from which the preferred invitation procedure can be derived. The following questions will therefore be answered:

1. Which subgroups prefer which invitation procedure?

2. Have different personal factors such as age, gender, social status, or family background influence or impact the preferred invitation procedure and willingness to participate in the SCS program?

\section{Inclusion Criteria}

Adult residents with a primary residence in the city of Munich aged $>35$ years will be included. Furthermore, participants need to have sufficient German-language skills to understand the general information provided about the project and to complete the online questionnaire.

\section{Survey Dissemination}

A random sample of the general population aged $>35$ years from the Munich area will be drawn from the local population registration office. The selected population will receive invitation letters with personalized 6-digit passwords (consisting of letters and numbers), which allow access to the online questionnaire. Additionally, the invitation letter will include a scannable QR code directly leading to the online questionnaire. Before answering the questionnaire, participants will have to confirm that they have read the general information provided online, including information about data protection. After this step, informed consent will be obtained online. Those who do not respond to the invitation will not be contacted again. The recruitment period is estimated to take 4 months. The questionnaire will be made available to the participants through a web-based survey tool, such as SurveyMonkey (Momentive Inc) or LimeSurvey (Carsten Schmitz and LimeSurvey Team). Each participant contacted may only take part in the survey once. The questionnaires will be numbered consecutively for data entry but will not be linked to participant-identifying information to ensure irreversible anonymity. We chose Munich as it is the capital city of Bavaria and has a larger number of available residents. In addition, we believe that the project will benefit from an intercity design as views from a medium-sized city (Erlangen) and one of the largest cities in Germany (Munich) will be included. No incentive will be offered for completion of the survey.

\section{Questionnaire Development}

Since there are currently no validated survey instruments tailored to the aim of our study, the questionnaire will be developed de novo based on the results from the focus group discussions as well as an assessment of the literature and dermato-oncological expertise. The questionnaire will consist of a multiple-choice format and will address sociodemographic data as well as previous participation in the SCS program. Further questions will elaborate the participants' preferred invitation and communication procedure. Before final dissemination, the questionnaire will be pretested and validated for clarity and comprehension by independent researchers who will not be involved in the design of the original questionnaire and volunteering patients from University Hospital Erlangen. Unclear items will be thoroughly discussed and rephrased until a consensus on clarity is reached. Based on this feedback, the questionnaire will be revised to its final version. The first draft of the questionnaire can be obtained from Multimedia Appendix 2 .

\section{Data Analysis and Sample Size Calculation}

The sample size calculation is based on a significance level of $\alpha=.05$ with a minimum effect size of $30 \%$ and a response rate of $20 \%$ in Munich. At least 500 questionnaires are needed to 
detect an actual significant effect; therefore, at least 2500 participants should be contacted since we expect a low response rate of $20 \%$. Descriptive analysis and multinomial logistic regression models will be performed to identify relevant correlations. The preferred invitation procedure will be used as the dependent variable, while age, willingness to participate, and other risk factors will serve as independent variables. Furthermore, chi-square tests or exact Fisher tests will be performed to investigate correlations between the sociodemographic variables and the individual questions. To counteract the problem of multiple testing, the Bonferroni correction method will be applied. A cluster analysis will be performed to discover patterns or similarities within the participants. Categorical variables will be expressed as frequencies and percentages, and continuous variables as median and range. A $P$ value $<.05$ will be considered as statistically significant. The statistical analyses will be performed with SAS (SAS Institute). This subproject will be guided by the Strengthening the Reporting of Observational Studies in Epidemiology (STROBE) statement [18].

\section{Results}

The study was approved by the institutional review board of University Hospital Erlangen (August 2020). The manual for the focus group discussions has been created. Recruitment for the focus group sessions started in February 2021 and is ongoing. We expect to end enrollment in the qualitative study in September 2021 and to finish the analysis in December 2021. The second part of the study will then start in January 2022. This study is expected to conclude in the summer of 2022.

\section{Discussion}

The HELIOS project aims to determine target group-specific invitation strategies to ultimately facilitate an increase in SCS participation rates in Germany, and thus lead to an earlier detection of skin cancer. Based on the results, suitable and motivating invitation and communication procedures can be implemented in the future. Therefore, our study will contribute to the realization of the goals of the National Cancer Plan in the field of dermato-oncology. In addition, the HELIOS project should contribute to the realization of the goals of the SCS such as the reduction of mortality and morbidity in Germany. Importantly, this project consists of 2 distinct subprojects in order to include the views of both patients with skin cancer and unaffected individuals.

While SCS was implemented more than 10 years ago based on the evidence derived from the results of the SCREEN study, SCS acceptance at the population level remains highly controversial $[19,20]$. SCS itself is noninvasive and does not cause any relevant damage. However, unnecessary biopsies as a result of false-positive examinations and overdiagnosis need to be kept in mind. A further point of criticism is that no reduction in melanoma mortality has been observed thus far after the implementation of the nationwide SCS, which contrasts with the results of the pilot project [21]. The reasons for this discrepancy remain unclear. One possible reason is that the performance of the 2 screening programs differ in some aspects
[22]. Whereas in the national SCS only dermatologists and general practitioners conduct the screening, in the SCREEN project general practitioners, gynecologists, urologists, and surgeons were also involved. Furthermore, the initiators of the SCREEN study concluded that the preceding public promotion prior to the implementation of the SCREEN project may have contributed to the success of the project [6].

In Germany, mammography screening is currently performed as an organized screening program. It was established between 2005 and 2009 and is based on an invitation system. All women between the ages of 50 and 69 years are invited to get screened with a mammography every 2 years and are informed about the screening offer by means of a leaflet. The overall participation rate among 5,528,937 invited women in 2015 was $51.5 \%$. Depending on the federal state, the participation rates ranged between $43 \%$ and $63 \%$ [23]. In a cross-sectional study with 13,144 women in 2014-2015, an even higher participation rate with $74.2 \%$ was described. Of these, $80.7 \%$ cited the invitation letter to account for participation [24]. Since July 2019, colorectal cancer screening has been implemented as a nationwide, risk group-adapted, organized program in Germany [25]. Following the promising participation rates of mammography in Germany as well as the decision to implement colorectal cancer screening and cervical cancer screening as an organized screening program, it is necessary to also investigate and derive communication strategies for SCS to increase participation rates.

A potential barrier to carrying out the focus group discussion in the first subproject is participant recruitment. If an insufficient number of people agree to participate, the recruitment period will have to be extended. In a next step, we will have to adjust the subgroup distribution and broaden, for example, the age restrictions. If participant numbers still remain low, we will have to critically discuss within our project coordination team whether we will perform focus group discussions with less than 5 persons or whether we will perform individual interviews. Due to the current COVID-19 pandemic and the subsequent social-distancing regulations, we are unsure whether focus group discussions are feasible. Nevertheless, we are confident that we can assemble a desirable number of participants for the discussions since we will use various recruitment strategies, such as patient support groups (including a Facebook group with more than 2000 active members), active contact through physicians, and flyers. Besides this, participants will receive an incentive, which will also be a motivation to engage in the discussions. Additionally, recruitment for the second subproject bears the risk of a low response rate since residents in the Munich area are often skeptical of surveys [26,27]. To counteract a small sample size and the consequent underpowering of our results, we will contact at least 2500 participants in order to obtain at least 500 data sets. Further, we will provide a scannable QR code that directly leads to the online questionnaire in order to facilitate accessibility.

Overall, the results of the HELIOS study will enable us to derive suitable evidence-based invitation and communication strategies for SCS. These may be implemented in the future to facilitate increased SCS uptake and early skin cancer detection. 


\section{Acknowledgments}

The authors thank all the patients for their willingness to participate.

$\mathrm{CB}$ is a member of the German Dermatologic Society (Deutsche Dermatologische Gesellschaft), a board member of the Dermatologic Cooperative Oncology Group (Arbeitsgemeinschaft Dermatologische Onkologie) of the German Cancer Society (Deutsche Krebsgesellschaft), a board member of the Nationale Versorgungskonferenz Hautkrebs, and a member of the UV-Schutz-Bündnis.

This study is supported by a grant from the German Cancer Aid (grant 70113659).

\section{Conflicts of Interest}

None declared.

\section{Multimedia Appendix 1}

Focus group guide for part 1 of the project.

[DOCX File, 18 KB-Multimedia Appendix 1]

\section{Multimedia Appendix 2}

Draft of the questionnaire for part 2 of the project.

[DOCX File , 48 KB-Multimedia Appendix 2]

\section{References}

1. Leiter U, Eigentler T, Garbe C. Epidemiology of skin cancer. Adv Exp Med Biol 2014;810:120-140. [doi: 10.1007/978-1-4939-0437-2 7] [Medline: 25207363]

2. Kornek T, Augustin M. Skin cancer prevention. J Dtsch Dermatol Ges 2013 Apr;11(4):283-298 [FREE Full text] [doi: 10.1111/ddg.12066] [Medline: 23574893]

3. Federman DG, Kirsner RS, Viola KV. Skin cancer screening and primary prevention: facts and controversies. Clin Dermatol 2013;31(6):666-670. [doi: 10.1016/j.clindermatol.2013.05.002] [Medline: 24160270]

4. Augustin M, Stadler R, Reusch M, Schäfer I, Kornek T, Luger T. Skin cancer screening in Germany - perception by the public. J Dtsch Dermatol Ges 2012 Jan;10(1):42-49. [doi: 10.1111/j.1610-0387.2011.07761.x] [Medline: 21923730]

5. Anders MP, Nolte S, Waldmann A, Capellaro M, Volkmer B, Greinert R, et al. The German SCREEN project--design and evaluation of the communication strategy. Eur J Public Health 2015 Feb;25(1):150-155. [doi: 10.1093/eurpub/cku047] [Medline: 24760725]

6. Katalinic A, Waldmann A, Weinstock MA, Geller AC, Eisemann N, Greinert R, et al. Does skin cancer screening save lives?: An observational study comparing trends in melanoma mortality in regions with and without screening. Cancer 2012 Nov 01;118(21):5395-5402 [FREE Full text] [doi: 10.1002/cncr.27566] [Medline: 22517033]

7. Eisemann N, Waldmann A, Katalinic A. [Incidence of melanoma and changes in stage-specific incidence after implementation of skin cancer screening in Schleswig-Holstein]. Bundesgesundheitsblatt Gesundheitsforschung Gesundheitsschutz 2014 Jan;57(1):77-83. [doi: 10.1007/s00103-013-1876-1] [Medline: 24357176]

8. Waldmann A, Nolte S, Weinstock MA, Breitbart EW, Eisemann N, Geller AC, et al. Skin cancer screening participation and impact on melanoma incidence in Germany--an observational study on incidence trends in regions with and without population-based screening. Br J Cancer 2012 Feb 28;106(5):970-974 [FREE Full text] [doi: 10.1038/bjc.2012.22] [Medline: 22294187]

9. Eissing L, Schäfer I, Strömer K, Kaufmann R, Enk A, Reusch M, et al. [Perception of statutory skin cancer screening in the general population: Current findings on participation, knowledge and evaluation]. Hautarzt 2017 May;68(5):371-376. [doi: 10.1007/s00105-017-3943-2] [Medline: 28246676]

10. Trautmann F, Meier F, Seidler A, Schmitt J. Effects of the German skin cancer screening programme on melanoma incidence and indicators of disease severity. Br J Dermatol 2016 Nov;175(5):912-919. [doi: 10.1111/bjd.14758] [Medline: 27203791]

11. Starker A, Saß A. Inanspruchnahme von Krebsfrüherkennungsuntersuchungen. Bundesgesundheitsbl 2013 May 25;56(5-6):858-867 [FREE Full text] [doi: 10.1007/s00103-012-1655-4]

12. Anastasiadou Z, Schäfer I, Siebert J, Günther W, Reusch M, Augustin M. Participation and health care provision of statutory skin cancer screening in Germany - a secondary data analysis. J Eur Acad Dermatol Venereol 2016 Mar;30(3):424-427. [doi: 10.1111/jdv.13559] [Medline: 26856813]

13. Früherkennungsfaltblatt Hautkrebs Erkennen. Deutsche Krebshilfe. URL: $\underline{\text { https://www.krebshilfe.de/fileadmin/Downloads/ }}$ PDFs/Praeventionsfaltblaetter Frueherkennung/FB-427 Hautkrebs-erkennen.pdf [accessed 2021-07-02]

14. Mays N, Pope C. Rigour and qualitative research. BMJ 1995 Jul 08;311(6997):109-112 [FREE Full text] [Medline: 7613363]

15. Mason J. Qualitative Researching, 2nd ed. London, UK: SAGE Publications; 2002. 
16. Mayring P. Qualitative Inhaltsanalyse. In: Flick U, von Kardoff E, Keupp H, von Rosenstiel L, Wolff S, editors. Handbuch qualitativer Forschung: Grundlagen, Konzepte, Methoden und Anwendungen. Munich, Germany: Beltz - Psychologie Verl Union; 1991:209-213.

17. Tong A, Sainsbury P, Craig J. Consolidated criteria for reporting qualitative research (COREQ): a 32-item checklist for interviews and focus groups. Int J Qual Health Care 2007 Dec;19(6):349-357 [FREE Full text] [doi: 10.1093/intqhc/mzm042] [Medline: 17872937$]$

18. von Elm E, Altman DG, Egger M, Pocock SJ, Gøtzsche PC, Vandenbroucke JP. The Strengthening the Reporting of Observational Studies in Epidemiology (STROBE) Statement: guidelines for reporting observational studies. Int J Surg 2014 Dec;12(12):1495-1499 [FREE Full text] [doi: 10.1016/j.ijsu.2014.07.013] [Medline: 25046131]

19. Stang A, Garbe C, Autier P, Jöckel K. The many unanswered questions related to the German skin cancer screening programme. Eur J Cancer 2016 Sep;64:83-88. [doi: 10.1016/j.ejca.2016.05.029] [Medline: 27371911]

20. Stang A, Jöckel K, Heidinger O. Skin cancer rates in North Rhine-Westphalia, Germany before and after the introduction of the nationwide skin cancer screening program (2000-2015). Eur J Epidemiol 2018 Mar;33(3):303-312. [doi: 10.1007/s10654-017-0348-6] [Medline: 29294207]

21. Boniol M, Autier P, Gandini S. Melanoma mortality following skin cancer screening in Germany. BMJ Open 2015 Sep 15;5(9):e008158 [FREE Full text] [doi: 10.1136/bmjopen-2015-008158] [Medline: 26373399]

22. Katalinic A, Eisemann N, Waldmann A. Skin Cancer Screening in Germany. Documenting Melanoma Incidence and Mortality From 2008 to 2013. Dtsch Arztebl Int 2015 Sep 18;112(38):629-634 [FREE Full text] [doi: 10.3238/arztebl.2015.0629] [Medline: 26429634]

23. Kääb-Sanyal V, Hand E. Jahresbericht Evaluation 2015. Deutsches Mammographie-Screening-Programm. Berlin, Germany: Kooperationsgemeinschaft Mammographie; 2017. URL: https://fachservice.mammo-programm.de/download/ evaluationsberichte/Jahresbericht-Evaluation_2015.pdf [accessed 2021-11-25]

24. Starker A, Kraywinkel K, Kuhnert R. Früherkennung von Brustkrebs: Inanspruchnahme der Mammografie in Deutschland. J of Health Monitoring 2017;4(2):74-80. [doi: 10.17886/RKI-GBE-2017-114]

25. Darmkrebs-Screening künftig als organisiertes Programm. Gemeinsamer Bundesausschuss. 2018. URL: https://www. g-ba.de/downloads/34-215-756/26 2018-07-17 oKFE Darmkrebs.pdf [accessed 2020-06-01]

26. Greif V, Batinic B. Die Bedeutung des Einladungsschreibens für die Rücklaufquote in Online-Befragungen. In: Jahrbuch der Absatz- und Verbrauchsforschung. Berlin, Germany: Duncker \& Humblot; 2007:162-177.

27. Kirchberg J, Fritzmann J, Clemens J, Oppermann N, Johannink J, Kirschniak A, et al. [The suffering surgeon-How do German surgeons protect themselves?: Survey of the German Society of General and Visceral Surgery on the extent of occupational safety measures and health burden among German surgeons]. Chirurg 2021 Feb 18;92(12):1114-1122 [FREE Full text] [doi: 10.1007/s00104-021-01365-1] [Medline: $\underline{\text { 33599806] }}$

\title{
Abbreviations \\ COREQ: Consolidated Criteria for Reporting Qualitative Research \\ HELIOS: Hautkrebsspezifische Einladungsverfahren zur informierten Screeningteilnahme (Skin Cancer-Specific Invitation Strategies to Participate in the Skin Cancer Screening Program) \\ SCREEN: Skin Cancer Research to Provide Evidence for Effectiveness in Northern Germany \\ SCS: skin cancer screening \\ STROBE: Strengthening the Reporting of Observational Studies in Epidemiology
}

\author{
Edited by $G$ Eysenbach; submitted 07.07.21; peer-reviewed by F Heppt, J Makin; comments to author 03.09.21; revised version \\ received 10.09.21; accepted 10.09.21; published 13.12.21 \\ Please cite as: \\ Steeb T, Heppt MV, Erdmann M, Wessely A, Klug SJ, Berking C \\ Increasing Participation Rates in Germany's Skin Cancer Screening Program (HELIOS): Protocol for a Mixed Methods Study \\ JMIR Res Protoc 2021;10(12):e31860 \\ URL: https://www.researchprotocols.org/2021/12/e31860 \\ doi: $10.2196 / 31860$ \\ PMID:
}

(CTheresa Steeb, Markus V Heppt, Michael Erdmann, Anja Wessely, Stefanie J Klug, Carola Berking. Originally published in JMIR Research Protocols (https://www.researchprotocols.org), 13.12.2021. This is an open-access article distributed under the terms of the Creative Commons Attribution License (https://creativecommons.org/licenses/by/4.0/), which permits unrestricted use, distribution, and reproduction in any medium, provided the original work, first published in JMIR Research Protocols, is 
properly cited. The complete bibliographic information, a link to the original publication on https://www.researchprotocols.org, as well as this copyright and license information must be included. 